\title{
A Simple Method for Estimating Effective Ion Source Residence Time
}

\author{
K. S. Griffith and Gregory I. Gellene \\ Department of Chemistry and Biochemistry, Texas Tech University, Lubbock, Texas, USA
}

\begin{abstract}
A method is presented that uses the well-understood $\mathrm{O}_{2} / \mathrm{Ar}$ ion-molecule reaction system to determine the effective ion source residence time of a chemical ionization source. The process consists of: (1) defining the kinetic system in terms of reactions, reaction rates, and ionization cross sections; (2) solving the differential equations that describe the time evolution of the kinetic system, and (3) comparing the calculated results to experimentally measured relative ion intensities. These steps are repeated for a variety of $\mathrm{O}_{2} /$ Ar sample ratios and inlet pressures. The method leads to a simple relationship between inlet pressure and effective ion source residence time, independent of the $\mathrm{O}_{2} / \mathrm{Ar}$ sample ratio. (I Am Soc Mass Spectrom 1993, 4, 787-791)
\end{abstract}

\section{$\mathrm{F}$} Tor over twenty years, chemical ionization (CI) has been used to elucidate information about the structure and identity of organic compounds [1]. CI mass spectra are generally quite different from electron ionization (EI) spectra, and are often more informative. In CI mass spectrometry, the ionization of the "unknown" material is produced by reactions with an ionized reagent gas. The spectra produced are characteristic of the particular reagent gas used. Typical reagent gases include deuterium oxide, methane, ammonia, and nitric oxide [2]. The extent of CI depends on the amount of time that the sample and reagent gases spend in the ionization source. This residence time, $t_{r}$, while of experimental interest, is often an unknown quantity and is dependent on the pressure inside the ionization source $\left(\mathrm{P}_{\text {so }}\right)$. This article presents a simple method for estimating an effective ion source residence time as a function of inlet pressure $\left(\mathrm{P}_{\text {in }}\right)$. The effective ion source residence time, $\tilde{t}_{r}$, is defined as the apparent time available for source ions to undergo reactions if $P_{s o}$ is taken to be equal to $P_{i n}$. Because $P_{\text {in }}$ and $P_{\text {so }}$ can be very different from one another, $t_{t}$ and $\tilde{t}_{r}$ can also differ considerably. However, under the usual pseudo-first-order conditions of a CI source, knowing $\tilde{t}_{r}$ and $P_{i n}$ is sufficient to predict the extent of the ion-molecule reactions in the source.

\section{Methods}

\section{Instrumentation}

Shown in Figure 1 is the ion source used in this study. Ions are produced initially by EI of the inlet gas.

Address reprint requests to Dr. Gregory I. Gellene, Department of Chemistry and Biochemistry, Texas Tech University, Lubbock, TX 79409-1061.
Ionizing electrons are produced from a hot Re filament located externally to the ion source with total emission current regulated. The ionizing energy $\left(\mathrm{E}_{\mathrm{e}}\right)$ was taken to be the nominal voltage between the filament and the source, and $\mathbf{E}_{\mathrm{e}}$ for this investigation was kept constant at $80 \mathrm{eV}$. Ions exiting the source are accelerated to 5 $\mathrm{keV}$, magnetically mass resolved, and detected by a channeltron electron multiplier. Various $\mathrm{O}_{2} / \mathrm{Ar}$ mixtures were used in this study, and $P_{\text {in }}$ ranged from 0.32-1.60 torr, as measured by a capacitance manometer. All experiments were done at $300 \mathrm{~K}$.

\section{Ion-Molecule Reaction System}

The $\mathrm{O}_{2}^{+}$internal state distribution produced by $\mathrm{EI}$ with $E_{e}=80 \mathrm{eV}$ initially consists of ions in the $X^{2} \Pi_{g}, a^{4} \Pi_{u}$, $A^{2} \Pi_{g}, b^{4} \Sigma_{g}^{-}$, and dissociative $B^{2} \Sigma_{g}^{-}$, states $\left[3_{-}^{-8}\right]$. The lifetimes of the $A^{2} \Pi_{g}$ and $b^{4} \sum_{g}^{-}$states are sufficiently short $[3,4]$ as to assume the $\mathrm{O}_{2}^{+}$ions participating in the ion-molecule reactions consist of only $X^{2} \Pi_{g}$ and metastable $\mathrm{a}^{4} \Pi_{\mathrm{u}}$ state ions $\left(\mathrm{O}_{2}^{+}\right.$and $\mathrm{O}_{2}^{+*}$, respectively). While it is possible that a variety of excited $\mathrm{Ar}^{+}$states are produced in the initial ionization step, none of these excited states should live long enough to be considered in the reaction system, as the doublet and quartet terms are well cornected by observed intersystem combinations $[9,10]$. Additionally, $\mathrm{O}^{+}$ions will also be present in the source in both ground $\left({ }^{4} S_{3 / 2}\right.$, $\left.\mathrm{O}^{+}\right)$and excited $\left({ }^{2} \mathrm{D}_{j}\right.$ and $\left.{ }^{2} \mathrm{P}_{\mathrm{j}}, \mathrm{O}^{+*}\right)$ states. $\mathrm{O}^{+}$and $\mathrm{O}^{+*}$ reactions with $\mathrm{Ar}$ are sufficiently slow as to be neglected [11]. Thus, there are five relevant ion-molecule reactions for the $\mathrm{O}_{2} / \mathrm{Ar}$ kinetic system [11-13]:

$$
\mathrm{O}_{2}^{+*}+\mathrm{Ar} \rightarrow \mathrm{O}_{2}+\mathrm{Ar}^{+} \quad \mathrm{k}_{1}=5.0 \times 10^{-10} \mathrm{~cm}^{3} \mathrm{~s}^{-1}
$$




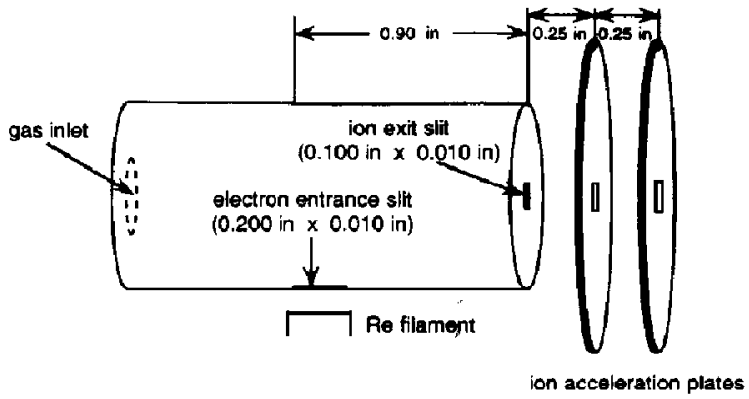

Figure 1. Diagram of the chemical ionization source used in this investigation.

$$
\begin{aligned}
\mathrm{O}_{2}+\mathrm{Ar}^{+} \rightarrow \mathrm{O}_{2}^{+}+\mathrm{Ar} & \mathrm{k}_{2}=6.3 \times 10^{-11} \mathrm{~cm}^{3} \mathrm{~s}^{-1} \\
\mathrm{O}_{2}^{+*}+\mathrm{O}_{2} \rightarrow \mathrm{O}_{2}^{+}+\mathrm{O}_{2} & \mathrm{k}_{3}=3.1 \times 10^{-10} \mathrm{~cm}^{3} \mathrm{~s}^{-1} \\
\mathrm{O}^{+}+\mathrm{O}_{2} \rightarrow \mathrm{O}+\mathrm{O}_{2}^{+} & \mathrm{k}_{4}=1.6 \times 10^{-11} \mathrm{~cm}^{3} \mathrm{~s}^{-1} \\
\mathrm{O}^{+*}+\mathrm{O}_{2} \rightarrow \mathrm{O}+\mathrm{O}_{2}^{+} & \mathrm{k}_{5}=8.1 \times 10^{-10} \mathrm{~cm}^{3} \mathrm{~s}^{-1}
\end{aligned}
$$

Because [neutrals] $>$ [ions] under the present experimental conditions, the time evolution of the kinetic system is well described by the coupled first-order linear differential equations:

$$
\begin{gathered}
\frac{\mathrm{d}\left[\mathrm{O}_{2}^{+}\right]}{\mathrm{dt}}=\mathrm{k}_{2}^{\prime}\left[\mathrm{Ar}^{+}\right]+\mathrm{k}_{3}^{\prime}\left[\mathrm{O}_{2}^{+*}\right]+\mathrm{k}_{4}^{\prime}\left[\mathrm{O}^{+}\right]+\mathrm{k}_{5}^{\prime}\left[\mathrm{O}^{+*}\right] \\
\frac{\mathrm{d}\left[\mathrm{O}_{2}^{+*}\right]}{\mathrm{dt}}=-\mathrm{k}_{1}^{\prime}\left[\mathrm{O}_{2}^{+*}\right]-\mathrm{k}_{3}^{\prime}\left[\mathrm{O}_{2}^{+*}\right] \\
\frac{\mathrm{d}\left[\mathrm{Ar}^{+}\right]}{\mathrm{dt}}=\mathrm{k}_{1}^{\prime}\left[\mathrm{O}_{2}^{+*}\right]-\mathrm{k}_{2}^{\prime}\left[\mathrm{Ar}^{+}\right] \\
\frac{\mathrm{d}\left[\mathrm{O}^{+}\right]}{\mathrm{dt}}=-\mathrm{k}_{4}^{\prime}\left[\mathrm{O}^{+}\right] \\
\frac{\mathrm{d}\left[\mathrm{O}^{+*}\right]}{\mathrm{dt}}=-\mathrm{k}_{5}^{\prime}\left[\mathrm{O}^{+*}\right]
\end{gathered}
$$

where $k_{1}^{\prime}=k_{1}[A R], k_{2}^{\prime}=k_{2}\left[O_{2}\right], k_{3}^{\prime}=k_{3}\left[O_{2}\right], k_{4}^{\prime}=$ $k_{4}\left[\mathrm{O}_{2}\right]$, and $k_{5}^{\prime}=k_{5}\left[\mathrm{O}_{2}\right]$. Integration of eqs 6-10 leads to:

$$
\begin{aligned}
{\left[\mathrm{O}_{2}^{+}\right]=} & {\left[\mathrm{O}_{2}^{+}\right]_{\mathrm{o}}-\left[\mathrm{Ar}^{+}\right]_{\mathrm{o}}\left(\mathrm{e}^{-\mathrm{k}_{2}^{\prime} \mathrm{t}}-1\right) } \\
& -\left[\mathrm{O}^{+}\right]_{0}\left(\mathrm{e}^{-\mathrm{k}_{4}^{\prime} \mathrm{t}}-1\right)-\left[\mathrm{O}^{+*}\right]_{0}\left(\mathrm{e}^{-\mathrm{k}_{5}^{\prime} t}-1\right) \\
& +\left[\mathrm{O}_{2}^{+*}\right]_{0}\left(\frac{\mathrm{k}_{1}^{\prime} \mathrm{e}^{-\mathrm{k}_{2}^{\prime} \mathrm{t}}}{\left\{\mathrm{k}_{2}^{\prime}-\mathrm{k}_{1}^{\prime}-\mathrm{k}_{3}^{\prime}\right\}}\right. \\
& \left.-\frac{\left(\mathrm{k}_{1}^{\prime} \mathrm{k}_{2}^{\prime}+\mathrm{k}_{3}^{\prime}\left\{\mathrm{k}_{2}^{\prime}-\mathrm{k}_{1}^{\prime}-\mathrm{k}_{3}^{\prime}\right\}\right) \mathrm{e}^{-\left\{\mathrm{k}_{1}^{\prime}+\mathrm{k}_{3}^{\prime}\right\} t}}{\left\{\mathrm{k}_{1}^{\prime}+\mathrm{k}_{3}^{\prime}\right\}\left\{\mathrm{k}_{2}^{\prime}-\mathrm{k}_{1}^{\prime}-\mathrm{k}_{3}^{\prime}\right\}}+1\right)
\end{aligned}
$$

$$
\begin{gathered}
{\left[\mathrm{O}_{2}^{+*}\right]=\left[\mathrm{O}_{2}^{+*}\right]_{\mathrm{o}} \mathrm{e}^{-\left\{\mathrm{k}_{1}^{\prime}+\mathrm{k}_{3}^{\prime}\right\} t}} \\
{\left[\mathrm{Ar}^{+}\right]=\frac{\left[\mathrm{O}_{2}^{+*}\right]_{\mathrm{o}} \mathrm{k}_{1}^{\prime}\left\{\mathrm{e}^{-\left\{\mathbf{k}_{1}^{\prime}+\mathrm{k}_{3}^{\prime}\right\} t}-\mathrm{e}^{-\mathrm{k}_{2}^{\prime} \mathrm{t}}\right\}}{\left\{\mathrm{k}_{2}^{\prime}-\mathrm{k}_{1}^{\prime}-\mathrm{k}_{3}^{\prime}\right] \mathrm{A}}+\left[\mathrm{Ar}^{+}\right]_{\mathrm{o}} \mathrm{e}^{-\mathrm{k}_{2}^{\prime} \mathrm{t}}} \\
{\left[\mathrm{O}^{+}\right]=\left[\mathrm{O}^{+}\right]_{\mathrm{o}} \mathrm{e}^{-\mathrm{k}_{4}^{\prime} \mathrm{t}}} \\
{\left[\mathrm{O}^{+*}\right]=\left[\mathrm{O}^{+*}\right]_{\mathrm{o}} \mathrm{e}^{-\mathrm{k}_{5}^{\prime} t}}
\end{gathered}
$$

In eqs 11-15, []$_{0}$ are the initial ion concentrations given by:

$$
\begin{aligned}
{\left[\mathrm{O}_{2}^{+}\right]_{\mathrm{O}} } & =\mathrm{S}\{1-\alpha\} \sigma_{\mathrm{O}_{2}}\left[\mathrm{O}_{2}\right] \\
{\left[\mathrm{O}_{2}^{+*}\right]_{\mathrm{O}} } & =\mathrm{S} \alpha \sigma_{\mathrm{O}_{2}}\left[\mathrm{O}_{2}\right] \\
{\left[\mathrm{Ar}^{+}\right]_{\mathrm{O}} } & =\mathrm{S} \sigma_{\mathrm{Ar}_{\mathrm{r}}}[\mathrm{Ar}] \\
{\left[\mathrm{O}^{+}\right]_{\mathrm{O}} } & =\mathrm{S}\{\mathrm{I}-\beta\} \sigma_{\mathrm{O}}\left[\mathrm{O}_{2}\right] \\
{\left[\mathrm{O}^{+*}\right]_{\mathrm{O}} } & =\mathrm{S} \beta \sigma_{\mathrm{O}}\left[\mathrm{O}_{2}\right]
\end{aligned}
$$

where $\sigma$ is the $80 \mathrm{eV}$ cross section for ionization $\left(1.57 \times 10^{-16} \mathrm{~cm}^{2}, 2.5 \times 10^{-16} \mathrm{~cm}^{2}\right.$, and $0.8 \times 10^{-16}$ $\mathrm{cm}^{2}$ for $\mathrm{O}_{2}, \mathrm{Ar}$, and $\mathrm{O}$ from $\mathrm{O}_{2}$, respectively [14-16]), $\alpha$ is the fraction of $\mathrm{O}_{2}^{+}$ions initially produced in the excited state at $80 \mathrm{eV}(\alpha=0.33$ [17]), $\beta$ is the fraction of $\mathrm{O}^{+}$ions initially produced in the excited states at 80 $\mathrm{eV}(\beta=0.30[17])$, and $\mathrm{S}=[\text { total ions }]_{\mathrm{O}} /\left(\sigma_{\mathrm{O} 2}\left[\mathrm{O}_{2}\right]+\right.$ $\left.\sigma_{0}\left[\mathrm{O}_{2}\right]+\sigma_{\mathrm{Ar}}[\mathrm{Ar}]\right)$. In general, determination of $S$ is difficult, and cannot be done readily for our ion source. However, if ion ratios are compared instead of individual ion intensities, the results are independent of $S$.

Ion loss due to diffusion to the walls of the source can be a complex problem in an ion-molecule reaction scheme. However, the choice of the $\mathrm{O}_{2} / \mathrm{Ar}$ system simplifies this consideration. Because $\mathrm{Ar}^{+}$and $\mathrm{O}_{2}^{+}$ ions have nearly identical mobilities in $\mathrm{Ar}[18]$, the $\left[\mathrm{Ar}^{+}\right] /\left[\mathrm{O}_{2}^{+}\right]$ratio is largely unaffected by the diffusion of $\mathrm{Ar}^{+}$and $\mathrm{O}_{2}^{+}$to the walls. The reaction rate of $\mathrm{O}^{+*}$ with $\mathrm{O}_{2}$ is sufficiently fast (approximately $80 \%$ of the Langevin collision rate), so that under present source conditions, diffusional wall loss of $\mathrm{O}^{+*}$ can be ignored. Alternatively, the reaction of $\mathrm{O}^{+}$with $\mathrm{O}_{2}$ is sufficiently slow so that it does not react significantly in the time scale of interest. Thus, diffusion effects can be neglected in the system.

The Relationship of $P_{\text {so }}$ and $P_{\text {in }}$

The residence time is dependent upon the concentration of all species in the source $\left([\mathrm{i}]_{\mathrm{sa}}\right)$, which is related to the inlet pressure through:

$$
[\mathrm{i}]_{\mathrm{so}}=\frac{\mathrm{P}_{\mathrm{i}, \mathrm{so}}}{\mathrm{k}_{\mathrm{B}} \mathrm{T}}=\frac{\gamma_{\mathrm{i}}(\mathrm{P}, \mathrm{T}) \mathrm{P}_{\mathrm{i}, \mathrm{in}}}{\mathrm{k}_{\mathrm{B}} \mathrm{T}}=\gamma_{1}(\mathrm{P}, \mathrm{T})[\mathrm{i}]_{\mathrm{in}}
$$


where $P_{i \text { so }}$ is the partial pressure of species $i$ inside the source, $P_{i, \text { in }}$ is the partial pressure of species $i$ as measured at the inlet, $k_{B}$ is Boltzmann's constant, $T$ is the absolute temperature, and $\gamma_{i}(P, T)$ is the proportionality function between $P_{i, s o}$ and $P_{i, \text { in }}$. Insight into $\gamma_{i}$ can be obtained by modeling flow into the source with Poiseulle's formula for flow through a tube and flow out of the source by Graham's law of effusion. In such a model, the rate of change in the number of molecules of species $i$ in the source $\left(d_{i}, s o / d t\right)$ is given by [19]:

$$
\frac{\mathrm{dN}_{\mathrm{i}, \mathrm{io}}}{\mathrm{dt}}=\frac{\pi \mathrm{r}^{4} \mathrm{P}_{\mathrm{i}, \mathrm{in}}\left(1-\gamma_{\mathrm{i}}^{2}\right)}{\mathrm{k}_{\mathrm{B}} \mathrm{T} 16 / \eta}-\frac{\gamma_{\mathrm{i}} \mathrm{P}_{\mathrm{i}, \mathrm{in}} \mathrm{A}}{\sqrt{2 \pi \mathrm{m}_{\mathrm{i}} \mathrm{k}_{\mathrm{B}} \mathrm{T}}}
$$

where $r$ is the radius of the inlet gas tube, $l$ is the length of the inlet gas tube, $\eta$ is the viscosity of the inlet gas, $m_{i}$ is the mass of the species $i$, and $A$ is the area of the escape apertures on the source. Under steady-state conditions, $\mathrm{dN}_{\mathrm{i}, \mathrm{so}} / \mathrm{dt}=0$ so that eq 22 can be solved for $\boldsymbol{\gamma}_{\mathrm{i}}$ giving:

$$
\gamma_{i}=\frac{1}{2}\left[\frac{-P_{i}}{P_{i, i n}} \pm\left(\frac{P_{i}^{2}}{P_{i, i n}^{2}}+4\right)^{1 / 2}\right]
$$

where only the positive combination is physically meaningful and $P_{i}$ is given by:

$$
\mathrm{P}_{\mathrm{i}}=\frac{16 \mathrm{~A} \ln }{\pi \mathrm{r}^{4}}\left(\frac{\mathrm{k}_{\mathrm{B}} \mathrm{T}}{2 \pi \mathrm{m}_{\mathrm{i}}}\right)^{1 / 2}
$$

which is independent of pressure at low pressures. In the limit of high and low $P_{i, i n}, \gamma_{i}$ can be approximated by:

$$
\begin{gathered}
\gamma_{i} \approx 1-\frac{P_{i}}{2 P_{i, \text { in }}} \quad\left(P_{i, i n}>P_{i}\right) \\
\gamma_{i}=\frac{P_{i, \text { in }}}{P_{i}} \quad\left(P_{i, \text { in }} P_{i}\right)
\end{gathered}
$$

From eq 24 and the parameters of the ion source, $\mathrm{P}_{\mathrm{Ar}} \approx 27$ torr and $\mathrm{P}_{\mathrm{O}_{2}} \approx 26$ torr are calculated, indicating that the present experiments were performed under the low pressure conditions ( $P_{i, i n}<2$ torr) where eq $25 \mathrm{~b}$ is valid, and that the gas-flow characteristics of the source can be reasonably approximated by a single $\gamma$. It is important to note that under the pseudo-first-order kinetic conditions of the ion source, this single $\gamma$ is also the proportionality constant between $t_{r}$ and $\tilde{t}_{r}$ (i.e., $\tilde{t}_{r}=\gamma t_{r}$ ). Thus, in the low pressure limit, it is expected that $\tilde{t}_{r}$ will vary with the square of $P_{\text {in }}$ because $\gamma$ is proportional to $P_{\text {in }}$ and $t_{r}$ is proportional to $P_{\mathrm{so}}[18]$ which is taken to be $P_{\text {in }}$ in the determination of $\tilde{\mathrm{t}}_{\mathrm{r}}$.
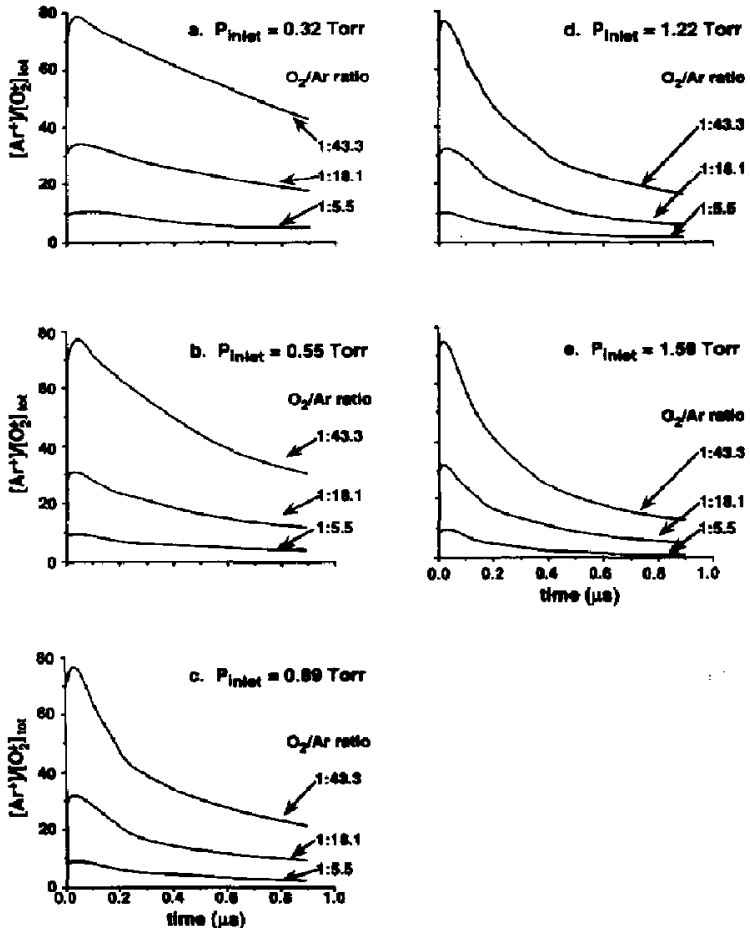

Figure 2. Variation of the calculated $\left[\mathrm{Ar}^{+}\right] /\left[\mathrm{O}_{2}^{+}\right]_{\text {tot }}$ ratio as a function of time for three different initial $\mathrm{Ar} / \mathrm{O}_{2}$ compositions and five different inlet pressures.

\section{Results}

The ratio of argon ion concentration to total oxygen ion concentration:

$$
\frac{\left[\mathrm{Ar}^{+}\right]}{\left[\mathrm{O}_{2}^{+}\right]_{\text {tot }}}=\frac{\left[\mathrm{Ar}^{+}\right]}{\left[\mathrm{O}_{2}^{+*}\right]+\left[\mathrm{O}_{2}^{+}\right]}
$$

was calculated as a function of time, total pressure, and $\mathrm{O}_{2} / \mathrm{Ar}$ composition using eqs 11-15. The results of these calculations are shown in Figure $2 a-e$. Since $\mathrm{O}_{2}^{+}$is the ultimate product in this ion-molecule kinetic system, $\left[\mathrm{Ar}^{+}\right] /\left[\mathrm{O}_{2}^{+}\right]_{\text {tot }}$ will approach zero at long times. By comparing the experimentally measured $\mathrm{Ar}^{+} / \mathrm{O}_{2}^{+}$intensity ratio with the calculated ion concentration ratios, $\bar{t}_{r}$ for a particular inlet pressure and $\mathrm{O}_{2}$ /Ar composition were determined (Figure 3a). As anticipated, $\overrightarrow{\mathrm{t}}_{\mathbf{r}}$ is a quadratic function of pressure with a plot of $t_{I} / P_{i n}$ vs $P_{\text {in }}$ being linear (Figure 3b), and because $\mathrm{O}_{2}$ and Ar have similar polarizabilities [21], $\tilde{\mathrm{t}}_{\mathbf{r}}$ is largely unaffected by the $\mathrm{O}_{2} / \mathrm{Ar}$ composition.

\section{Discussion}

In principle, the kinetic scheme could be simplified by operating at $\mathrm{E}_{\mathrm{e}} \leq 16 \mathrm{eV}$, which would eliminate the need to consider excited ionic states. However, at such 

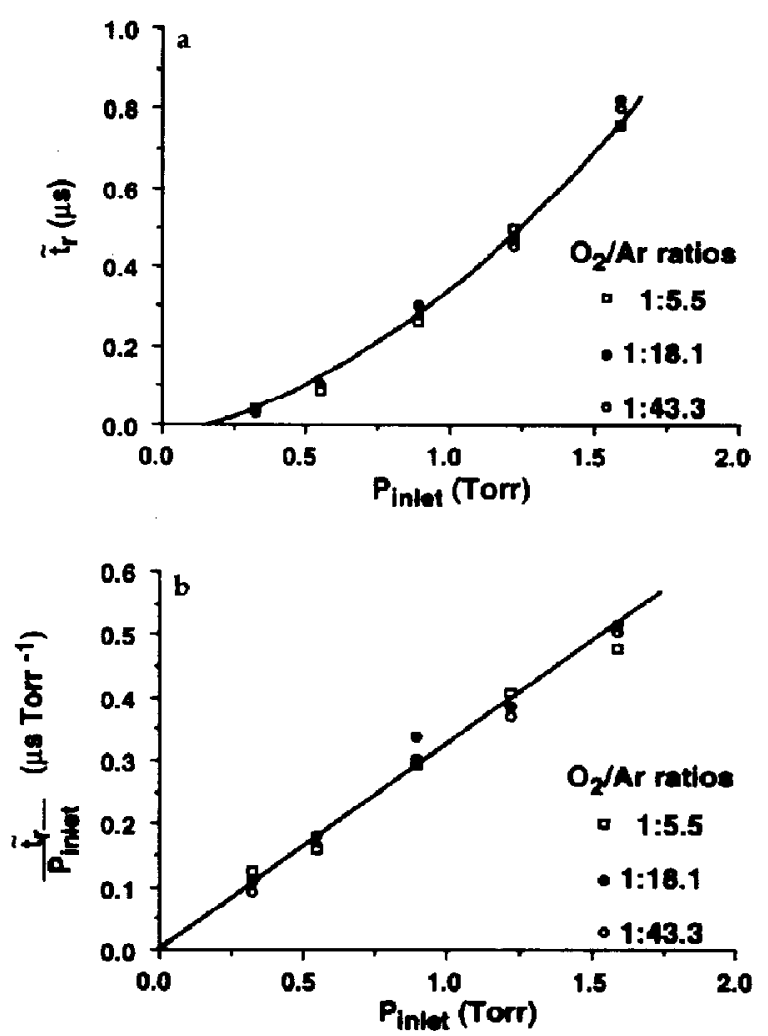

Figure 3. (a) Effective ion source residence time as a function of inlet pressure for three different initial Ar $/ \mathrm{O}_{2}$ compositions; (b) the ratio of effective ion source residence time to inlet pressure as a function of inlet pressure.

low $\mathrm{E}_{\mathrm{e}}, \sigma_{\mathrm{O}_{2}}$ and $\sigma_{\mathrm{Ar}}$ are strong functions of $\mathrm{E}_{\mathrm{e}}$ [14-16], causing the relative initial ion concentrations to depend on the details of the (unknown) $\mathrm{E}_{\mathrm{e}}$ distribution. 'Ihus, it was determined to be advantageous to operate at $80 \mathrm{eV}$ and consider the kinetics in detail.

It would be useful to have this type of analysis for a variety of commonly used gases; however, this can be impractical. The analysis requires detailed knowledge of the electronic states of all species in the ion source, as well as the kinetics of the system, generally including diffusion to the walls of the source. Such information is not readily available for more complicated systems, and thus it is more useful to scale the results of the $\mathrm{O}_{2} / \mathrm{Ar}$ characterization for other gases. Under conditions in which the composition of the source gas is dominated by a single component, the ion source residence time appropriate for an alternate major source gas $\left(\tilde{\mathfrak{t}}_{r}^{\prime}\right)$ can be estimated by scaling $\tilde{\mathbf{t}}_{\mathrm{r}}$ to account for changes in the rate of ions reaching the source exit and changes in $\gamma$. Ion mobility $(\kappa)$ is given by the Langevin mobility equation in the polarization limit [18] as:

$$
\kappa=\frac{0.5105}{(\rho(D-1))^{1 / 2}}\left(\frac{M+m}{m}\right)^{1 / 2}
$$

where $M$ is the mass of the bath gas, $m$ is the mass of the ion, $\rho$ is the density of the bath gas, D is the dielectric constant of the bath gas, and the constant is dimensionless. In the low pressure limit, viscosity of the source gas [19] is given by:

$$
\eta=\frac{2}{3 \pi \mathrm{d}_{\mathrm{i}}^{2}}\left(\frac{\mathrm{m}_{\mathrm{i}} \mathrm{k}_{\mathrm{B}} \mathrm{T}}{\pi}\right)^{1 / 2}
$$

where $d_{i}$ and $m_{i}$ are the collisional diameter and mass of the major source gas component, respectively. Substituting eq 28 into eq 24 leads to:

$$
P_{i}=\frac{16 \sqrt{2} A_{B} T l}{3 \pi^{3} \mathrm{r}^{4} d_{i}^{2}}
$$

indisating that $d_{i}$ is the only species-dependent parameter upon which $P_{i}$ depends. Therefore, within the polarization limit, the appropriate scaling in the low pressure limit is $\left.\tilde{\mathrm{t}}_{\mathrm{r}}^{\prime}=\left(\tilde{\mathrm{t}}_{\mathrm{r}} \kappa \mathrm{d}^{2^{\prime}}\right) / \boldsymbol{\kappa}^{\prime} \mathrm{d}_{\mathrm{i}}^{2}\right)$. In the high pressure limit, $\gamma \approx 1$ (eq 25a) and the scaling is given by $\tilde{\mathrm{t}}_{\mathrm{r}}^{\prime}=\tilde{\mathrm{t}}_{\mathrm{r}} \kappa / \kappa^{\prime}$.

\section{Acknowledgments}

We thank Dr. Bruce Plashko for measuring the compositions of the $\mathrm{O}_{2} /$ Ar samples. K.S.G. thanks the Henry Luce Foundation for graduate fellowship support during the portions of this investigation performed at the University of Notre Dame. Acknowledgment is made to the Donors of the Petroleum Research Fund administered by the American Chemical society (PRF No. 22721AC5) and to the National Science Foundation (Grant No. CHE9024091) for their support of this work.

\section{References}

1. Munson, M. S.; Field, F. H. Am. Chem. Soc. J. 1966, 88, 2621-2630.

2. Hunt, D. F. Adv. Mass Spectrom. 1974, 6, 517-522.

3. Krupenie, P. H. J. Phys. Chem. Ref. Data 1972, 1, 423-520.

4. Borst, W. L.; Zipf, E. C. Phys. Rev. A 1970, 1, 1410-1415.

5. McConkey, J. W.; Woolsey, J. M. J. Phys. B 1969, 2, 529-533.

6. Asundi, R. K.; Ramachandrarao, Ch. V. S. Chem. Phys. Lett. 1969, 89-92.

7. Nishimura, H. J. Phys, Soc. Japan 1968, 24, 130-143.

8. Doolittle, P. H.; Schoen, R. I.; Schubert, K. E. I. Chem. Phys. 1968, 49, 5108-5115.

9. Boyce, J. C. Phys. Rev. 1935, 48, 396-402.

10. de Bruin, T.L. Zeit. Phys. 1928, 51, 108-113.

11. Rowe, B. R.; Fahey, D. W.; Fehsenfeld, F. C.; Albritton, D. L. J. Chem. Phys. 1980, 73, 194-205. 
12. Lindinger, W.; Albritton, D. L.; McFarland, M.; Fehsenfeld, F. C.; Schmeltekopf, A. L.; Ferguson, E. E. J. Chem. Phys. 1975, $62,4101-4110$.

13. Gaucherel, P.; Rowe, B. Int. J. Mass Spectrom. Ion Phys. 1977, 25, 211-227.

14. Märk, T. D. J. Chem. Phys. 1975, 63, 3731-3736.

15. Stephan, K.; Helm, H,; Märk, T. D. J. Chemt. Phys. 1980, 73, 3763-3779.

16. Rapp, D.; Englander-Golden, P.; Briglia, D. D. J. Chem. Phys. 1965, 42, 4081-4085.
17. Turner, B. R.; Rutherford, J. A.; Compton, D. M J. J. Chem. Phys. 1968, 48, 1602-1608.

18. McDaniel, E. W. Collision Phenomena in Ionized Gases; Wiley: New York, 1964; pp 426-440.

19. Atkins, P. W. Physical Chemistry, 4th ed.; Freeman: New York, 1990; pp 733-741.

20. Hirschfelder, J. O.; Curtiss, C. F.; Bird, R. B. Molecular Theory of Gases and Liquids; Wiley: New York, 1967; pp 514-533.

21. Moelwyn-Hughs, E. A. Physical Chemistry; Pergamon: New York, 1957; p 373. 